\title{
Non-Invasive Distress Evaluation in Preterm Newborn Infants
}

\author{
C.Manfredi, Member IEEE, L.Bocchi, Member IEEE, S.Orlandi, M.Calisti, L.Spaccaterra, G.P.Donzelli
}

\begin{abstract}
With the increased survival of very preterm infants, there is a growing concern for their developmental outcomes. Infant cry characteristics reflect the development and possibly the integrity of the central nervous system. In this paper, relationships between fundamental frequency $\left(F_{0}\right)$ and vocal tract resonance frequencies $\left(F_{1}-F_{3}\right)$ are investigated for a set of preterm newborns, by means of a multi-purpose voice analysis tool (BioVoice), characterised by high-resolution and tracking capabilities. Also, first results about possible distress occurring during cry in preterm newborn infants, as related to the decrease of central blood oxygenation, are presented. To this aim, a recording system (Newborn Recorder) has been developed, that allows synchronised, non-invasive monitoring of blood oxygenation and audio recordings of newborn infant's cry. The method has been applied to preterm newborns at the Intensive Care Unit, A.Meyer Children Hospital, Firenze, Italy.
\end{abstract}

\section{INTRODUCTION}

Crying is a physiological action made by the infant to communicate and draw attention. Infant cry characteristics reflect the development and possibly the integrity of the central nervous system [8-13]. However, in preterm and/or low-birth-weight infants it could imply an effort which may have an adverse impact on blood oxygenation. In fact, preterm new born infants have an impaired auto regulation of the cerebral blood flow [1-4]. Irregularities in the blood flow and pressure may adversely influence the development of the child [5-7]. Some studies have been performed to evaluate both cerebral and peripheral blood oxygenation in the newborn by Near InfraRed Spectroscopy (NIRS) and pulse oximetry, also as linked to other techniques [1-7]. Our preliminary studies [14], [15] indicate that the distress effect of crying seems larger on central blood saturation than on peripheral saturation, hence here we will consider only central blood saturation as related to cry.

The aim of this paper is twofold: finding possible correlations between $F_{0}$ and $F_{1}-F_{3}$ and increasing gestational age (g.a.) and weight at birth (w.a.b.), and relating cry episodes with decrease in central blood oxygenation.

Manuscript received April 16, 2008. This work was supported in part by Ente Cassa di Risparmio di Firenze, project n.2007.0574.

C.Manfredi is with the Department of Electronics and Telecommunications, Faculty of Engineering, Università degli Studi di Firenze, Via S. Marta 3, 50139 Firenze, Italy (corresponding author. Phone: + 39- 055-4796410; fax: +39-055-494569; e-mail: manfredi@det.unifi.it).

L.Bocchi, S.Orlandi, and M.Calisti are with the Department of Electronics and Telecommunications, Faculty of Engineering, Università degli Studi di Firenze, Via S. Marta 3, 50139 Firenze, Italy. E-mail: leonardo.bocchi@unifi.it,orlandisilvia85@gmail.com,marcello.calisti@gm ail.com.

L.Spaccaterra and G.P.Donzelli are with the Department of Paediatrics, AOU A. Meyer-Università degli Studi di Firenze, Via L.Giordano, Firenze, Italy. E-mail: loreasp@yahoo.it, donzelli@unifi.it.
Objective analysis of cry signals was performed, to investigate the developmental characteristics of the vocal apparatus in the newborns. To relate central blood oxygenation with crying, a new recording system was developed, that allows non invasive, synchronised monitoring of blood oxygenation (NIRS spectrometer and pulse oximeter) and audio recordings of infant's cry emissions. Ad hoc markers allow for localisation of cry episodes in blood oxygenation recordings.

First results on a data set of 18 preterm infants point out a strict relationship between the decrease of $\mathrm{F}_{0}$ and $\mathrm{F}_{1}-\mathrm{F}_{3}$, as related to g.a. and w.a.b. Moreover, preliminary results show that the effort in crying seems directly linked to a decrease in the central blood oxygenation level during a cry episode, pointing out the need for specific care in preterm, low weight newborns, to minimise distress.

\section{MATERIALS AND METHODS}

\section{A. Synchronised data recording}

Central blood saturation was measured with a NIRS device (INVOS 5100C Somanetics Corp.), at a sampling rate of 0.2 samples/s. Peripheral blood oxygenation and heart rate were recorded with a pulse oximeter (Radical Masimo Set) employing powerful adaptive digital filters for denoising, at a sampling rate of $1 \mathrm{sample/s}$. A unidirectional microphone (Shure SM58), equipped with Tascam US-144 portable audio/MIDI interface $(96 \mathrm{kHz} / 24$-bit recording) was used to record cry emissions on a multimedia laptop, with a sampling frequency $\mathrm{Fs}=44 \mathrm{kHz}$ and 16 bit resolution.

Specific software (Newborn Recorder) was designed to synchronise the output of the three devices by means of a digital output linking the laptop with the input of both the NIRS and pulse oximeter devices. Simultaneous recordings of the audio channel trough the US-144 board and of the NIRS and pulse oximeter signal using a RS-232 connection has been implemented. Due to different sampling rates used for NIRS, pulse oximeter and audio signals, in order to synchronise data the range for audio analysis is adjusted to the nearest second in the corresponding NIRS recording. Markers are provided on the oxygenation recordings, corresponding to cry episodes. An example is shown in Fig.1, of about 30 mins length, with three markers $(\mathbf{\Delta})$, all corresponding to a decrease in blood oxygenation level during cry episodes The cry episode marked with (仓) is described later in Figs. 5-6.

Notice the decrease of $\mathrm{RO} 2$ around the time instants $0: 08: 35, \quad 0: 15: 35$ and in the interval 0:21.15-0:24:15. Missing data correspond to lost contact between sensors and patient's skin. Though Newborn Recorder also allows for synchronised recording of pulse oximetry, these data were 


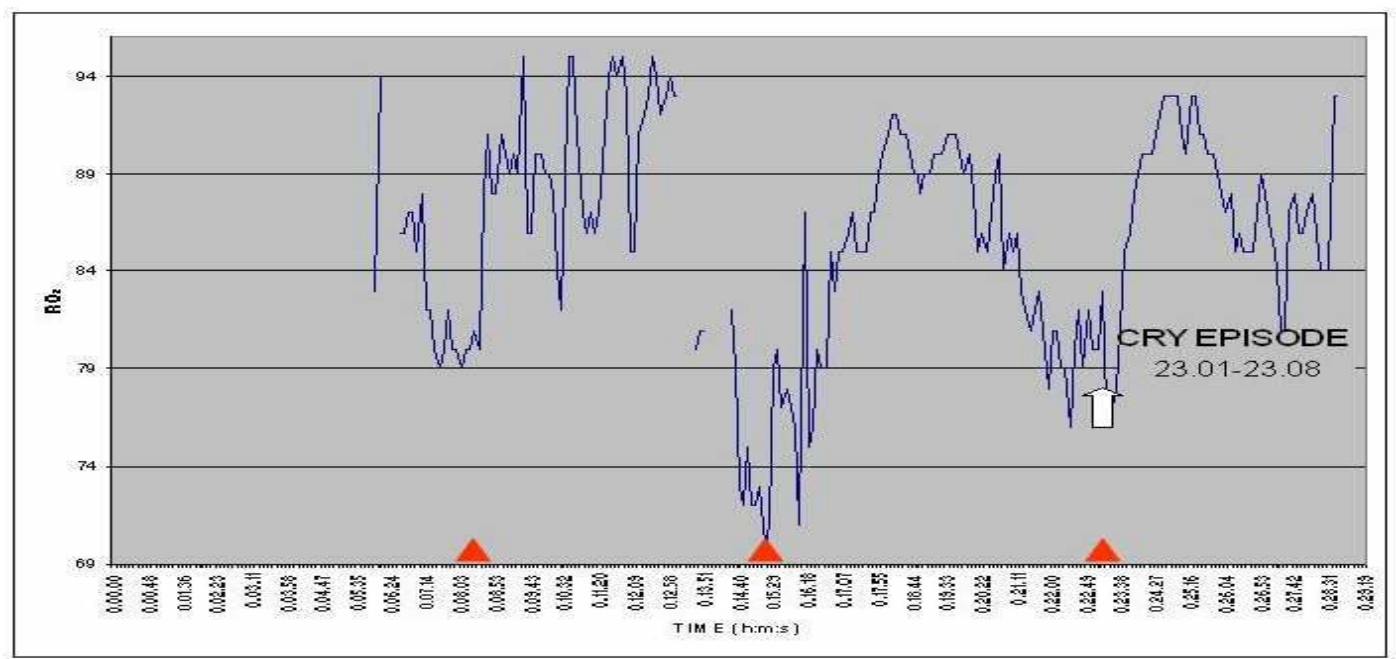

Fig. 1 - Example of NIRS recording (29.19 mins) with markers $(\boldsymbol{\Delta})$ on cry-episodes. The 3rd one pointed out with the arrow - about $5 \mathrm{~s}$ length corresponds to figures 5-6.

not considered in this study, and this will be done in further work.

Fig.2 shows the user-interface for patient data management (protected by privacy), newborn and mother anamnesis data settings and selected peripherals (top), and the devices synchronised with the new tool (below).

\section{B. Cry analysis}

Cry episodes ( $2 \mathrm{~s}-5 \mathrm{~s}$ length each) are automatically extracted from audio recordings by means of a new software tool working o ff-line, and then submitted to a multi-purpose voice analysis tool, named BioVoice [11], [15]. New-born infant cry is characterised by very high fundamental frequency $\left(\mathrm{F}_{0}\right)$ and resonance frequency (RFs) values, with abrupt changes and voiced/unvoiced (V/UV) features of very short duration in a single utterance. BioVoice is capable to perform high-resolution robust tracking of main acoustic parameters on quasi-stationary signal frames.

BioVoice has been developed to overcome some weakness commonly found in most commercial software. Specifically, no manual setting is required to the user, as the tool automatically adjusts internal settings for any input signal (depending on sex, age, sampling frequency, etc.). Fig.3 shows the user-friendly interface for BioVoice.

Moreover, on each cry episode a voiced/unvoiced (V/UV) separation algorithm is applied optimised to avoid parameter estimation on signal frames that have no harmonic content, where misleading results could be obtained. BioVoice implements new robust adaptive signal processing tools, and allows performing high-resolution $\mathrm{F}_{0}$ and resonance frequencies (RFs) tracking on signal frames of varying length (even few ms), adaptively tailored to varying signal characteristics [8-11].

Even if vowel frequencies cannot be found in newborn cry, RFs $\left(F_{i}, i=1 \ldots\right)$ reflect important acoustical characteristics of the vocal tract of the infant. Robust and high-resolution RFs estimation is implemented, based on parametric AutoRegressive (AR) PSD evaluation [8-11]. A number of plots and tables is displayed and saved in printable format, for a visual comparison of results. Specifically, $\mathrm{F}_{0}$, V/UV frames, spectrogram and the first three RFs, $F_{1}-F_{3}$, are plotted, all in coloured map. Tables summarise mean, std, max, min values for $F_{0}$ and $F_{1}-F_{3}$, as well as cry length and the corresponding maximum energy. These parameters are in fact considered among the most meaningful for newborn cry analysis [8-13].

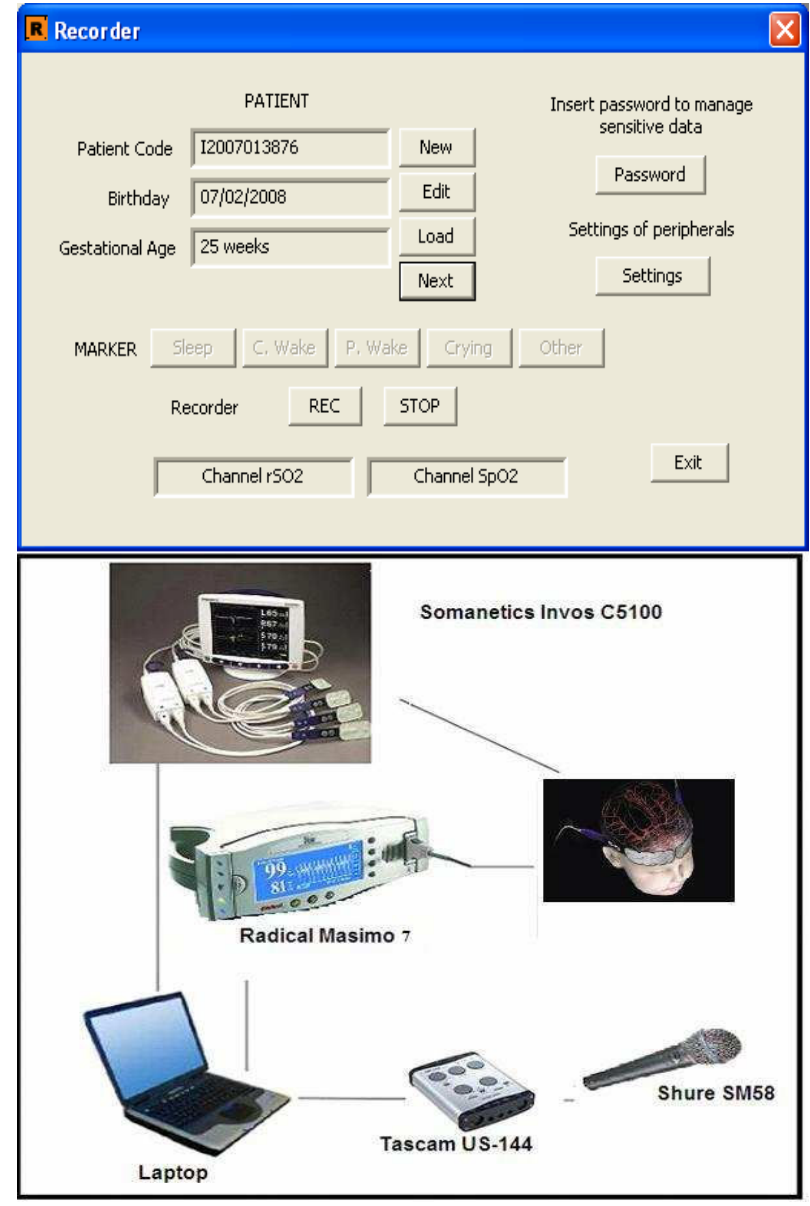

Fig. 2 - Top: Newborn Recorder: user interface with recording options, patient data storage and retrieval. Bottom: Devices for data acquisition and elaboration synchronised with Newborn Recorder. 


\section{EXPERIMENTAL RESULTS}

The analysis has been carried out on a group of 18 preterm and/or low weight infants plus 2 full term infants, having a gestational age (g.a.) ranging from 23 to 41 weeks and a weight at birth (w.a.b.) between $590 \mathrm{~g}$ and $3500 \mathrm{~g}$, selected by physicians among patients at the Critical Care Unit of the Children Hospital A. Meyer, in Firenze, Italy.

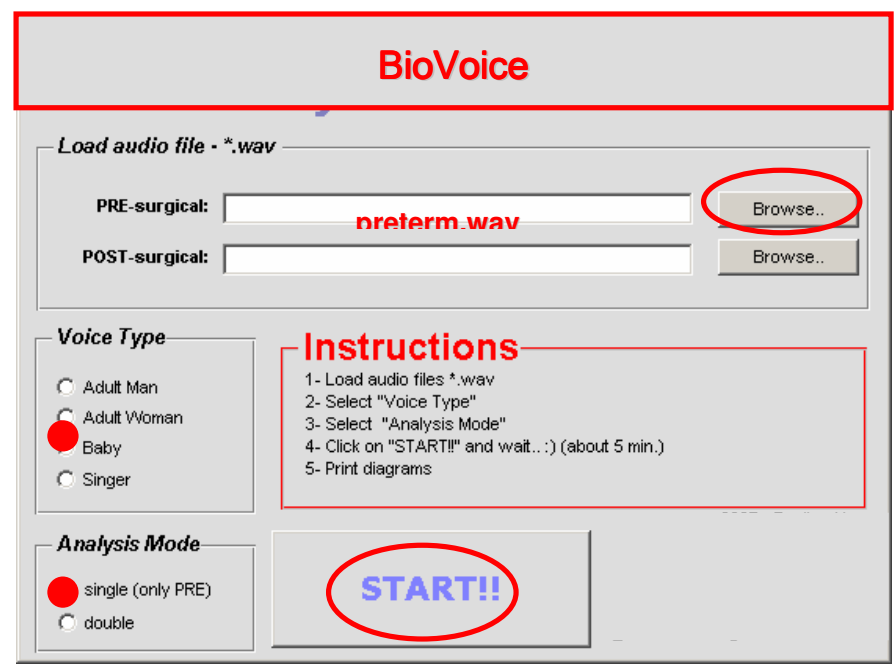

Fig.3 - The user-friendly interface of the multi-purpose voice analysis tool BioVoice.

No relevant pathology was found among the analysed infants. Notice that in most cases, due to staying for a due period in the incubator, recordings were made later (age > 35 weeks). Careful selection of a quiet room for recordings, as well as a stable level of illumination guaranteed good quality of recordings. The microphone was positioned at a fixed distance of $15 \mathrm{~cm}$ from the mouth of the newborn infant.

Three cry episodes were considered for each newborn infant, coming from a single recording or different ones.

\section{A. Cry analysis}

$\mathrm{F}_{0}$ and RFs $\mathrm{F}_{1}-\mathrm{F}_{3}$ were evaluated with BioVoice, and possible decrease in $\mathrm{F}_{0}$ and RFs with increasing g.a. and/or w.a.b. was analysed. Statistical comparison (t-test) between $\mathrm{F}_{0}, \mathrm{~F}_{1}$ and $\mathrm{F}_{2}$ has shown high significant statistical difference $(\mathrm{p}<<0.01)$ with all 20 cases grouped together. Moreover, $\mathrm{t}-$ test has also been applied to $F_{0}, F_{1}, F_{2}$ only for preterm data divided into two classes, according to g.a. ( $<34$ weeks or $>34$ weeks), and to w.a.b. ( $<2500 \mathrm{~g}$ or $>2500 \mathrm{~g})$, as suggested by clinicians. Results gave again high significant statistical difference $(\mathrm{p}<<0.01)$. Such results, to put into relation with the development of the phonatory apparatus in newborns, are in agreement with literature [10-13]. Fig.4 shows the boxplot for $F_{0}$. Similar boxplots are obtained for $F_{1}$ and $F_{2}$.

We point out that, among the analysed cry signals, few cases show the rising-falling melody for $\mathrm{F}_{0}$ typical of healthy fullterm newborns [10-12]. Instead, an irregular, low-energy behaviour was often noticed. Moreover, cry episodes were found of very short duration $(<1 s)$ and with energy decreasing with time, possibly due to the reduced breathing capabilities of patients. The same behaviour was found also for $F_{1}-F_{3}$. In particular, $F_{3}$ was highly irregular and thus scarcely informative. Figs. 5-6 show $\mathrm{F}_{0}$ tracking and the V/UV selection made by BioVoice on a cry episode of a newborn infant with g.a. $=27$ weeks and w.a.b. $=800 \mathrm{~g}$. Thanks to the high-resolution capabilities, even UV parts of few ms could be found. With BioVoice, tables summarising main cry characteristics (number of voiced parts in the cry episode, their mean, min and max values, and the maximum energy power of the whole cry episode) are also provided.

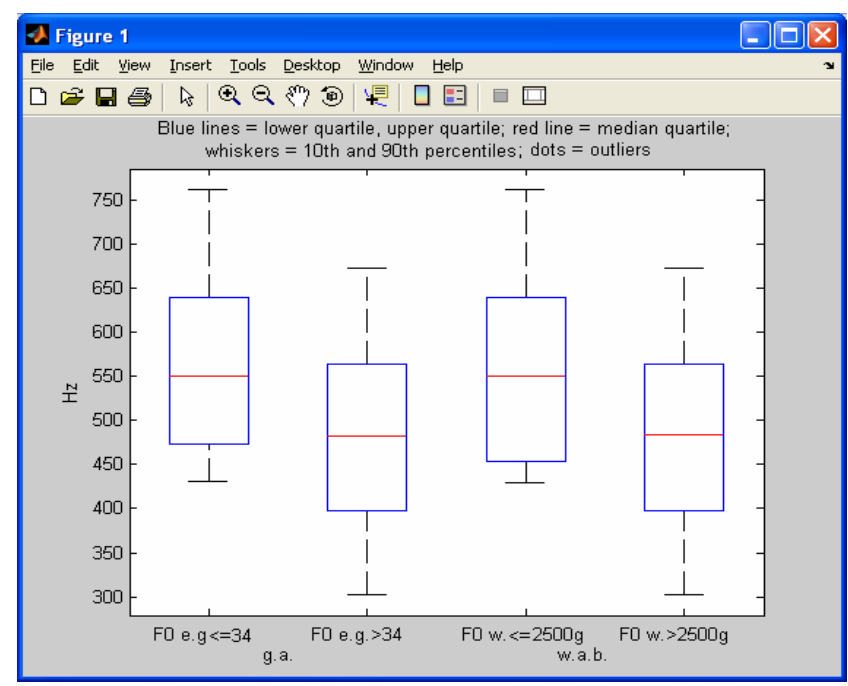

Fig. 4 - Boxplot showing the decrease of $F_{0}$ with increasing g.a. and w.a.b.

\section{B. NIRS analysis}

All cry episodes (three episodes for each subject) were related to the corresponding NIRS recordings to find out possible decrease in blood oxygenation linked to cry. Specifically, for 12 cases out of the whole data set, the three cry episodes considered for analysis belong to a single recording (Set 1), while in the other 8 cry episodes belong to different recordings (Set 2). This choice was due to the best quality of the selected cries. We point out that data were scarcely homogeneous, due to different situations occurred during recordings: cry episodes were sometimes close to each other, or well separated in other cases, and possibly preceded by sleep or awake ness, or other conditions. The mean value of the 15 NIRS values before the cry episode was considered as reference value. Better results were obtained for Set 1, with a $3.5 \%$ of decrease in blood oxygenation, while only $1 \%$ was obtained for Set 2 . Table 1 shows the results obtained applying the t-test on the two groups.

TABLE 1

PERCENTAGE OF NIRS DECREASE AND T-TEST RESULTS ON SET 1 AND 2.

\begin{tabular}{|c|c|c||}
\hline & Set 1 & Set 2 \\
\hline NIRS decrease & $3.5 \%$ & $1 \%$ \\
\hline t-test & $\mathrm{p}<0.01$ & $0.01<\mathrm{p}<0.05$ \\
\hline
\end{tabular}

Moreover, an increase of saturation after the cry episode was observed, possibly linked to the effort made by the nervous 
system to compensate the loss of oxygen due to crying [14][15].

To further compare cry and NIRS results, the mean of 5-1015 NIRS values (corresponding to about 25-50-75 s), respectively before and after each cry episode, was considered, for all cases. A t-test applied on such data (15 NIRS values) shows highly significant statistical difference $(\mathrm{p}<<0.01)$ between pre- and post crying NIRS values. NIRS values during cry episodes give highly significant statistical difference only with pre-crying NIRS data. Table 2 below summarises results.

TABLE 2

T-TEST RESULTS ON 15 PRE/POST CRY NIRS VALUES

\begin{tabular}{||c|c|c||}
\hline Cry ep./pre-cry & Cry ep./post-cry & Pre-cry/post-cry \\
\hline 0.0091 & 0.5142 & $1.053 \mathrm{E}-6$ \\
\hline
\end{tabular}

As already noticed, cry episodes occurred under different conditions: calm or tossed sleep, or awake ness, could precede and/or follow them. This could distort results. Hence, further work will be carried on under this respect.

\section{CONCLUSIONS}

First results have been presented, concerning the evaluation of the distress occurring during cry, as related to possible decrease of cerebral oxygenation. A synchronisation system has been developed, that allows simultaneously recording blood oxygenation and infant's cry emissions. A new robust tool for new-born infant cry analysis is presented. Preliminary results from a group of 18 preterm newborns show that in most cases drop in blood oxygenation seems directly related to the distress due to crying, pointing out the need for specific care in preterm infants, devoted to stress reduction. A control group made up by full term, standard w.a.b. newborns, is under construction for comparison.

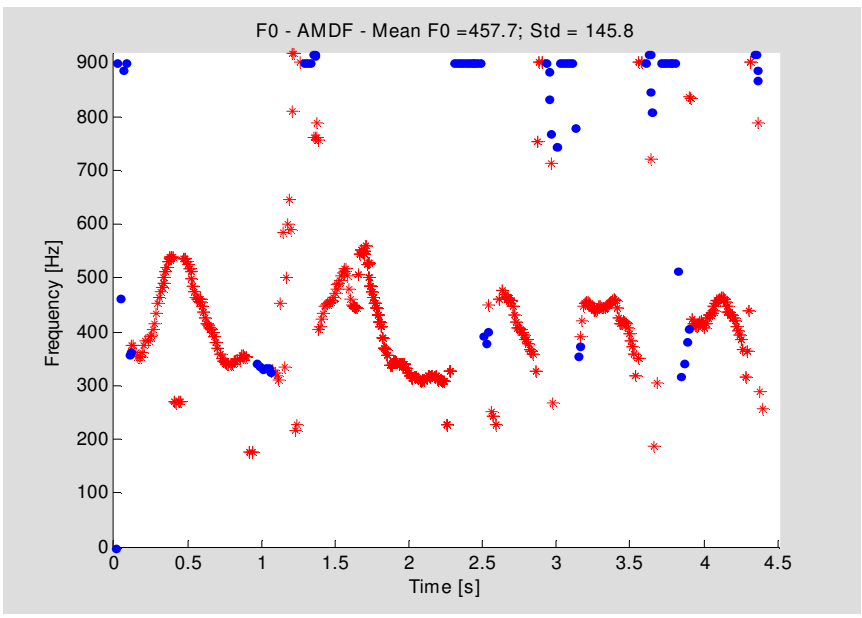

Fig. 5 - $\mathrm{F}_{0}$ tracking for a very preterm, low w.a.b. newborn. Mean and std values are also reported.

\section{ACKNOWLEDGEMENTS}

This work has been partially supported by "Ente Cassa di Risparmio di Firenze", under the project: n. 2006.1517
"Analisi di segnali ed immagini vocali per applicazioni biomediche", 2007.

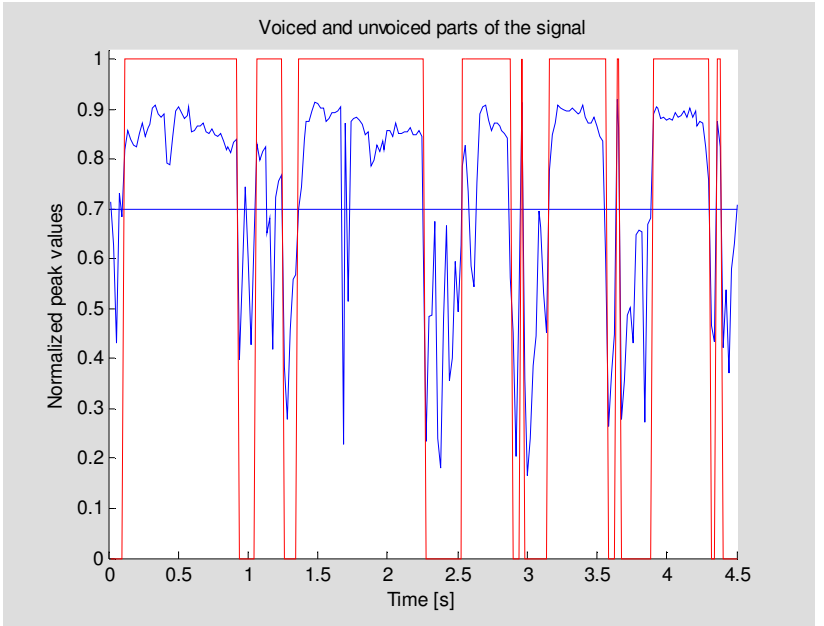

Fig. 6 - V/UV selection obtained with BioVoice

\section{REFERENCES}

[1] Pryds O. \& Edwards, A.D., "Cerebral blood flow in the newborn infant", Archives of Disease in Childhood: foetal and neonatal edition, 74 (1), pp. 63-69, (1996).

[2] Greisen G. "Cerebral blood flow preterm infant during the first week of life", Acta Paediatrica Scandinavica, 75, pp.43-51 (1986).

[3] Lou H.C., Lassen N.A. \& Frii-Hansen B., "Impaired autoregulation of cerebral blood flow in the distressed new born infant", Journal of Paediatrics, 94, 118-121, (1979).

[4] Miall-Allen V.M., de Vries L.S., Whitelaw A.G. (1987). Mean arterial blood pressure and neonatal cerebral lesion. Archives of Disease Childhood, 62, 1068-1069.

[5] Van De Bor M. \& Walther F.J., "Cerebral blood flow velocity regulation in preterm infant”, Biology of the Neonate, 59, pp. 329-335, (1991).

[6] Friis - Hansen B., "Perinatal brain injury and cerebral blood flow in newborn infant", Acta Paediatrica Scandinavica, 74, pp. 323-331, (1985).

[7] Delpy DT., Cope MC., Cady EB, Wyatt JS.,Hamilton PA., Hope PL, Wray S. \& Reynolds EO., "Cerebral monitoring in newborn infants by magnetic resonance and near infrared spectroscopy", Scandinavian Journal of Clinical Laboratory Investigation, 188, pp. 9-17, (1987).

[8] Fort, A. Ismaelli, C. Manfredi, P. Bruscaglioni, "Parametric and non parametric estimation of speech formants: application to infant cry", Medical Engineering and Physics, 18 (8), pp. 677-691(1996).

[9] Fort, C. Manfredi, "Acoustic analysis of new-born infant cry signals", Medical Engineering and Physics, 20 (6), pp.432-442 (1998).

[10]Wermke K., Mende W., Manfredi C., Bruscaglioni P., "Developmental Aspects of infant's Cry melody and Formants", Medical Engineering and Physics, 24 (7-8), pp. 501-514 (2002).

[11]Manfredi C., Tocchioni V., Bocchi L., "A robust tool for newborn infant cry analysis", $28^{\text {th }}$ Annual Int. Conf. IEEE EMBS, Aug.30- Sept. 3, 2006, New York City, U.S.A. (CD-ROM).

[12]Nicollas R., Ouaknine M., Giovanni A., Berger J., To J.P., Dumoulin D., Triglia J.M., " Physiology of vocal production in the newborn", Proc. $3^{\text {rd }}$ Int. Workshop MAVEBA, Firenze, Italy, December 2003, pp. 51-54.

[13] http://www.disat.unimib.it/bioacoustics/it

[14]Bocchi L., Spaccaterra L., Acciai F., Orlandi S., Favilli F., Atrei E., Manfredi C., Donzelli G.P., "Monitoring of preterm infants during crying episodes", $11^{\text {th }}$ Conference MEDICON 2007, Ljubljana, Slovenia, June 26-30, 2007.

[15]Bocchi L., Spaccaterra L., Acciai F., Orlandi S., Favilli F., Atrei E., Manfredi C., Donzelli G.P., "Blood oxygenation vs. cry in preterm newborn infants", Proc. $5^{\text {th }}$ Int. Workshop MAVEBA, Firenze, Italy, Dec. 2007, pp. 215-218 (2007). 